\title{
Photocatalytic Activity of Reactively Sputtered Titania Coatings Deposited Using a Full Face Erosion Magnetron
}

\author{
Nick Farahani $^{1}{ }^{*}$, Peter J. Kelly ${ }^{1}$, Glen West ${ }^{1}$, Claire Hill ${ }^{2}$ and Vladimir Vishnyakov ${ }^{3}$ \\ 1 Surface Engineering Group, Manchester Metropolitan University, Manchester, M1 5GD, UK; \\ E-Mails: peter.kelly@mmu.ac.uk (P.J.K.); g.west@mmu.ac.uk (G.W.) \\ 2 Millennium Inorganic Chemicals Ltd., a Cristal Global Company Grimsby, Lincolnshire, \\ DN40 2PR, UK; E-Mail: claire.hill@ cristal.com \\ 3 Dalton Research Institute, Manchester Metropolitan University, Manchester, M1 5GD, UK; \\ E-Mail: v.vishnyakov@mmu.ac.uk
}

* Author to whom correspondence should be addressed; E-Mail: nick.farahani@yahoo.co.uk; Tel.: +44-758-260-2084; Fax: +44-161-247-4693.

Received: 19 July 2013; in revised form: 22 September 2013 / Accepted: 14 October 2013 / Published: 25 October 2013

\begin{abstract}
Titanium dioxide (titania) is widely used as a photocatalyst for its moderate band gap, high photoactivity, recyclability, nontoxicity, low cost and its significant chemical stability. The anatase phase of titania is known to show the highest photocatalytic activity, however, the presence of this phase alone is not sufficient for sustained activity. In this study $\mathrm{TiO}_{2}$ coatings were deposited onto glass substrates by mid-frequency pulsed magnetron sputtering from metallic targets in reactive mode using a Full Face Erosion (FFE) magnetron, which allows the magnetic field to be modulated during the deposition process. The as-deposited coatings were analysed by scanning electron microscopy (SEM), energy dispersive X-ray spectroscopy (EDX) and micro-Raman spectroscopy. Selected coatings were then annealed at temperatures in the range of $400-700{ }^{\circ} \mathrm{C}$ and re-analysed. The photocatalytic activity of the coatings was investigated through measurements of the degradation of organic dyes, such as methyl orange, under the influence of UV and fluorescent light sources. It has been demonstrated that, after annealing, the pulsed magnetron sputtering process produced photo-active surfaces and that the activity of the coatings under exposure to fluorescent lamps was some $35 \%-45 \%$ of that observed under exposure to UV lamps.
\end{abstract}


Keywords: full face erosion magnetrons; magnetron sputtering; metal targets; photocatalytic coatings; Raman spectroscopy; methyl orange

\section{Introduction}

Titania (titanium dioxide) is a commercially important material with a wide range of applications, such as pigments, electronic data storage, sun screen and UV absorbers, anti-fogging screens, air and water purification devices and 'self-cleaning' windows [1-3]. Self-cleaning glass has a surface coating that keeps itself free of dirt and grime through natural photo-induced processes. The coating is commonly based on thin film titanium dioxide. The glass cleans itself in two stages. The photocatalytic stage of the process breaks down any organic material on the glass using ultraviolet radiation in sunlight. Oxygen vacancies created on the surface then makes the glass hydrophilic. Rain water will then form 'sheets' over the hydrophilic surface and rinse away the residue of the organic dirt [4-6]. Titanium dioxide in nature exists in one of three crystalline forms, anatase, rutile and brookite, and in thin film form, its structure is known to be highly sensitive to deposition conditions. Rutile is the thermodynamically stable form of titania; anatase is transformed to rutile at high deposition or post-annealing temperatures (in most cases above $700{ }^{\circ} \mathrm{C}$ ) [7-14]. Brookite is very rarely found in thin film form. Of these phases, it is the anatase form, or anatase/rutile mixed phase structures that are found to have the highest photocatalytic activity.

In this study, $\mathrm{TiO}_{2}$ coatings were deposited onto glass substrates by mid-frequency $(100-350 \mathrm{kHz})$ pulsed magnetron sputtering from metallic targets in reactive mode [15-23]. This technique is known to produce all forms of titania surfaces including highly photo-active anatase [24]. The full face erosion (FFE) magnetron used for the process, has the capability to oscillate the central pole at various speeds during operation. Consequently, the plasma sweeps across the central region of the target. This is designed to increase the area of the target that is sputtered, which improves target utilisation and, by keeping the central region of the target clean, also improves process stability by reducing the tendency for arcing particularly when depositing oxides [25]. This is a recent design of magnetron and the operating characteristics have not yet been investigated in detail. Thus, the influence of moving the central pole on the deposition process and the growing film is not fully understood.

A number of methods have been developed for the assessment of the photocatalytic activity of surfaces. For instance, for titania-based doped coatings the photocatalytic degradation of malic acid under UV and visible light irradiation were proposed [26,27]. Also, it was demonstrated that titania photocatalysts exhibit a significant level of activity against a broad spectrum of microorganisms [28]. However, the most widely used techniques for measuring photoactivity are based on photo-oxidation of organic films (such as stearic acid) or organic dyes. Depending on the property of the film layer a specific photocatalytic activity test, dry or wet is selected. For instance, whilst stearic acid (dry method) can produce non-continuous contacts between the stearic acid and the surface of the film [29-33], using methyl orange [34-36] or methylene blue [37] dyes can result in the production of continuous contact between the surface of the film and the solution. The latter method suits a photocatalytic test in which an electron exchange is involved and that was the major testing technique used for this study. 


\section{Experimental}

The titania coatings were deposited by reactive DC or mid-frequency pulsed magnetron sputtering from a $375 \mathrm{~mm} \times 125 \mathrm{~mm}$ Full Face Erosion magnetron. The target was $99.5 \%$ purity $\mathrm{Ti}$ and the reactive sputtering process was controlled by optical emission monitoring (the $503 \mathrm{~nm}$ Ti line was monitored and held at $20 \%$ of the full metal signal, as this had previously been shown to produce transparent titania coatings [38,39]). After achieving a base pressure of $1 \times 10^{-3} \mathrm{~Pa}$, argon was introduced to the chamber at 17.7 SCCM. The pumping set was then throttled in order to achieve the desired coating pressure (typically $0.1-0.2 \mathrm{~Pa}$ ). Coatings were deposited at an average power of $1.3 \mathrm{~kW}$ in either DC, or pulsed DC magnetron sputtering mode at frequencies of 100,225 or $350 \mathrm{kHz}$ and a duty of 50\%. The magnetron was operated at four different FFE configurations (0, i.e., static, 20, 150 or $300 \mathrm{rpm}$ ). These speeds were chosen to study the potential effect of FFE oscillation speed on the deposition process. In the static configuration the FFE magnetron is identical to a planar magnetron; $20 \mathrm{rpm}$ results in minimal disturbance to the plasma; $150 \mathrm{rpm}$ is the mid-range speed and $300 \mathrm{rpm}$ generates maximum plasma disturbance during each cycle. For these experiments a fixed run time of one hour was used. The target-to-substrate distance was $110 \mathrm{~mm}$. The coatings were deposited onto $4 \mathrm{~mm}$ float glass samples, size $150 \mathrm{~mm} \times 150 \mathrm{~mm}$, as well as glass microscope slides, all of which were ultrasonically pre-cleaned in iso-propanol.

The as-deposited coatings were analysed by scanning electron microscopy (SEM, Zeiss Supra 40, Zeiss, Cambridge, UK), energy dispersive X-ray spectroscopy (EDX, Edax Trident, EDAX, Leicester, UK), and micro-Raman spectroscopy (Renishaw Invia, $514 \mathrm{~nm}$ laser, Renishaw, Gloucestershire, UK). Selected coatings were annealed in air at temperatures in the range $400-700{ }^{\circ} \mathrm{C}$ for 10 min and re-analysed. Also, the coating thickness was measured by Dektak surface profilometry.

The photocatalytic activity of $\mathrm{TiO}_{2}$ films can vary significantly and is dependent on many factors, such as film thickness, roughness, crystallite size and crystal phase [40]. In this study the photocatalytic activity was assessed in two ways. An initial scan of the samples was made using the photo-reduction reaction of resazurin $(\mathrm{Rz})$ dye [41,42]. In brief, the formulation consists of: the redox dye, resazurin; a sacrificial electron donor, glycerol; and a polymer, hydroxyethyl cellulose, dissolved in water. Upon irradiation of the ink on a photocatalytic surface with ultra-violet radiation, the photogenerated electrons reduce the blue Rz to the pink resorufin (Rf) while the photogenerated holes oxidise the glycerol to glyceralaldehyde. This process occurs in minutes on an active surface, making this test particularly suited to "on the spot" tests, but it cannot be readily quantified. Two drops of Rz solution were applied to the surface of the samples (typically $20 \mathrm{~mm} \times 20 \mathrm{~mm}$ ) using a pipette. Then, a microscope slide $(20 \mathrm{~mm} \times 20 \mathrm{~mm}$ ) was placed onto the dye spot to spread the dye evenly over the whole sample surface. The coatings were irradiated at an integrated power flux of $4 \mathrm{~mW} / \mathrm{cm}^{2}$ with two 15 W 365 nm BLB lamps (Sankyo Denki; Farnell, Leeds, UK) until a blue-to-pink colour change was observed for the dye, or for a total period of $40 \mathrm{~min}$ (bulb to sample separation $=100 \mathrm{~mm}$ ). Based on the 'pass/fail' Rz test, selected samples were then re-tested against methyl orange solutions. Methyl orange (MeO 99.9\% pure, Alfa Aesar) was used as a simple model of a series of common azo-dyes widely used in industry [43]. When it is dissolved in distilled water, the MeO UV-vis spectrum shows a strong absorption peak at approximately $464 \mathrm{~nm}$. Changes in this reference peak were used to monitor the photocatalytic degradation of $\mathrm{MeO}$ by the titania coatings. Experiments were carried out at room 
temperature in air. The coatings were again irradiated at $4 \mathrm{~mW} / \mathrm{cm}^{2}$ with $365 \mathrm{~nm}$ BLB lamps. Samples of the $\mathrm{MeO}(0.06 \mathrm{M})$ solution were taken before testing and then at $30 \mathrm{~min}$ intervals up to a total time of 4 hours and analysed using a Perkin-Elmer UV-vis spectrophotometer. Spectra were taken in the range of $350-550 \mathrm{~nm}$ to monitor the absorption peak in this region. Also, tests were carried out using two $15 \mathrm{~W}$ fluorescent $(\mathrm{Fl})$ tubes in place of the UV tubes to simulate typical laboratory environments. The integrated power flux to the coatings with the Fl tubes was $6.4 \mathrm{~mW} / \mathrm{cm}^{2}$, of which the UV component (300-400 nm) was $0.5 \mathrm{~mW} / \mathrm{cm}^{2}$. In all other ways the tests were identical to the UV tests. A comparison of the spectra from the two light sources is given in Figure 1.

Figure 1. Spectra from UV and fluorescent tubes used for photocatalytic testing.

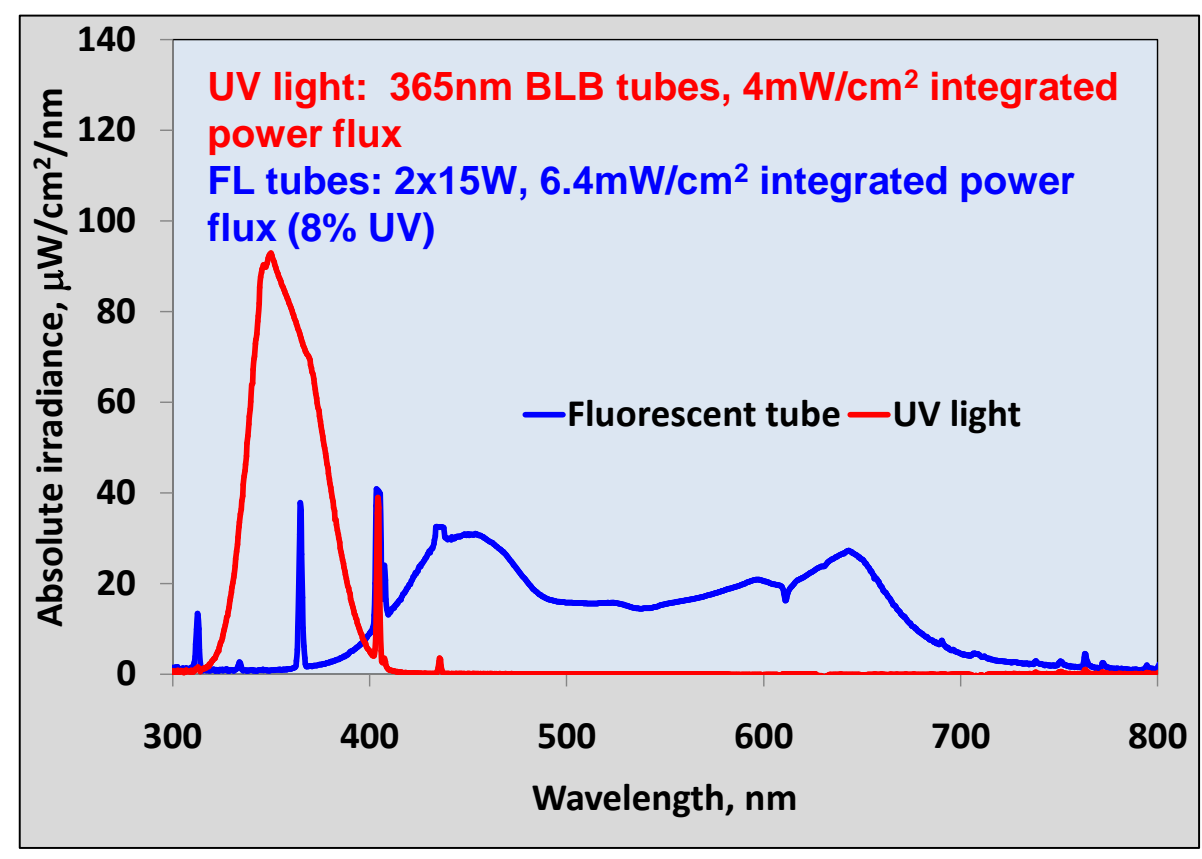

\section{Results}

\subsection{Coating Structures, Compositions and Deposition Rates}

\subsubsection{As-Deposited Coatings}

Coatings were deposited under a range of operating conditions, as listed in Table 1. Estimates of deposition rates and $R_{\mathrm{a}}$ roughness values of as-deposited coatings (from the Dektak surface profilometer) are presented in Table 1. The variation in deposition rate across the process envelope is significant, ranging from 20.4 to $34.4 \mathrm{~nm} / \mathrm{min}$. Furthermore, it is apparent that deposition rate decreases with increasing pulse frequency, but increases with increasing FFE speed (see Figure 2). The reduction in deposition rate with pulse frequency has been observed and is described elsewhere [44]. The influence of FFE oscillation speed on deposition rate has not, though, been previously reported. Although the mechanism resulting in the increase in deposition rate with oscillation speed is complex and needs further investigation, it is likely that the increase may be due to keeping the poisoned regions cleaner at higher speeds and the broader racetrack region means sputtering takes place from a greater surface area of the target. 
Table 1. Compositional and structural properties of reactively sputtered titania coatings at various operating parameters and annealing temperatures.

\begin{tabular}{|c|c|c|c|c|c|c|c|c|}
\hline \multirow{2}{*}{$\begin{array}{c}\text { Sample } \\
\text { No }\end{array}$} & \multirow{2}{*}{$\begin{array}{l}\text { Frequency, } \\
\quad(\mathbf{k H z})\end{array}$} & \multirow{2}{*}{$\begin{array}{c}\text { FFE } \\
\text { Oscillation } \\
\text { Speed, } \\
\text { rpm }\end{array}$} & \multirow{2}{*}{$\begin{array}{l}\text { Deposition } \\
\text { Rate, } \\
\text { nm/min }\end{array}$} & \multirow{2}{*}{$\begin{array}{c}R_{\mathrm{a}} \\
\text { Value, } \\
\mathbf{n m}\end{array}$} & \multicolumn{4}{|c|}{ Post-annealed Coatings } \\
\hline & & & & & $400{ }^{\circ} \mathrm{C}$ & $500{ }^{\circ} \mathbf{C}$ & $600{ }^{\circ} \mathrm{C}$ & $700{ }^{\circ} \mathrm{C}$ \\
\hline S1 & $\mathrm{DC}$ & - & 31.8 & 9 & $\mathrm{AM}$ & $\mathrm{AM}$ & RU & RU \\
\hline S2 & DC & 20 & 33.6 & 11 & $\mathrm{AM}$ & $\mathrm{AM}$ & RU & RU \\
\hline S3 & $\mathrm{DC}$ & 150 & 34.1 & 15 & $\mathrm{AM}$ & $\mathrm{AM}$ & RU & RU \\
\hline S4 & DC & 300 & 34.4 & 28 & $\mathrm{AM}$ & AN & $\mathrm{AN}$ & AN \\
\hline S5 & 100 & - & 25.8 & 17 & $\mathrm{AM}$ & $\mathrm{AM}$ & AN & AN/RU \\
\hline S6 & 100 & 20 & 26.9 & 20 & $\mathrm{AM}$ & AN & AN & $\mathrm{AN}$ \\
\hline S7 & 100 & 150 & 27.1 & 21 & $\mathrm{AM}$ & AN & AN & $\mathrm{AN}$ \\
\hline S8 & 100 & 300 & 27.5 & 19 & $\mathrm{AM}$ & AN/RU & AN/RU & AN/RU \\
\hline S9 & 225 & - & 25.1 & 27 & $\mathrm{AM}$ & AN & AN & AN/RU \\
\hline S10 & 225 & 20 & 26.2 & 29 & $\mathrm{AM}$ & AN/RU & AN/RU & AN/RU \\
\hline S11 & 225 & 150 & 26.8 & 29 & $\mathrm{AM}$ & AN/RU & AN/RU & AN/RU \\
\hline S12 & 225 & 300 & 27.1 & 30 & $\mathrm{AM}$ & AN/RU & AN/RU & AN/RU \\
\hline S13 & 350 & - & 20.4 & 15 & $\mathrm{AM}$ & $\mathrm{AM}$ & RU/AN & RU \\
\hline S14 & 350 & 20 & 22.1 & 9 & $\mathrm{AM}$ & $\mathrm{AM}$ & RU & RU \\
\hline S15 & 350 & 150 & 22.5 & 11 & $\mathrm{AM}$ & $\mathrm{AM}$ & RU & RU \\
\hline S16 & 350 & 300 & 23.3 & 12 & $\mathrm{AM}$ & $\mathrm{AM}$ & RU & RU \\
\hline
\end{tabular}

Notes: Structures determined by Raman spectroscopy. AM: Amorphous; AN: Anatase; RU: Rutile; AN/RU: Mixed phase with predominating anatase structure; RU/AN: Mixed phase with predominating rutile structure; FFE: Full Face Erosion magnetron.

Figure 2. Variation in deposition rate for titania coatings produced by DC and pulsed DC reactive magnetron sputtering using a Full Face Erosion (FFE) magnetron. Apparently, deposition rate decreases with increasing pulse frequency, but increases with increasing FFE speed.

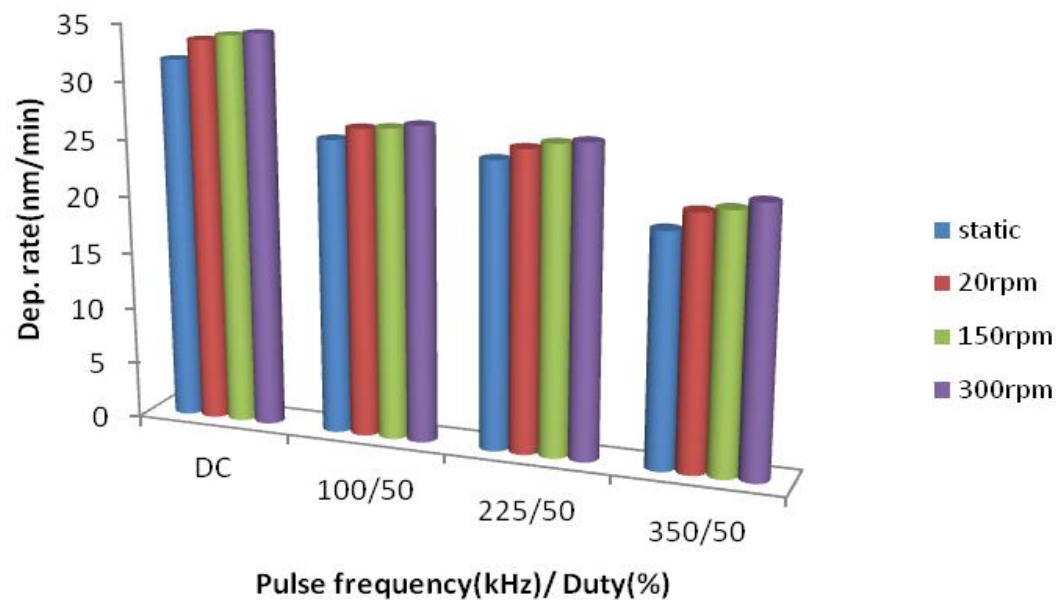

Figure 3 shows the effect of FFE oscillation speed on the structure of the as-deposited films while operating the magnetron discharge at $350 \mathrm{kHz}$ pulse frequency. At $300 \mathrm{rpm}$ the Raman spectra indicates a weak rutile structure, whereas in the static case, the structure appears to be amorphous. 
Figure $4 \mathrm{a}-\mathrm{d}$ is SEM micrograph of the surface and fracture sections of samples S13 and S16, respectively. Both have similar dense structures, but the difference in deposition rate observed with the FFE magnetic field stationary and rotating at $300 \mathrm{rpm}$ is apparent from the difference in film thickness between the samples.

Figure 3. Raman spectra for titania samples S13 (FFE static) and S16 (FFE $300 \mathrm{rpm}$ ) deposited at $350 \mathrm{kHz}$ onto glass substrates-As-deposited. (Notes: A: Anatase; R: Rutile).

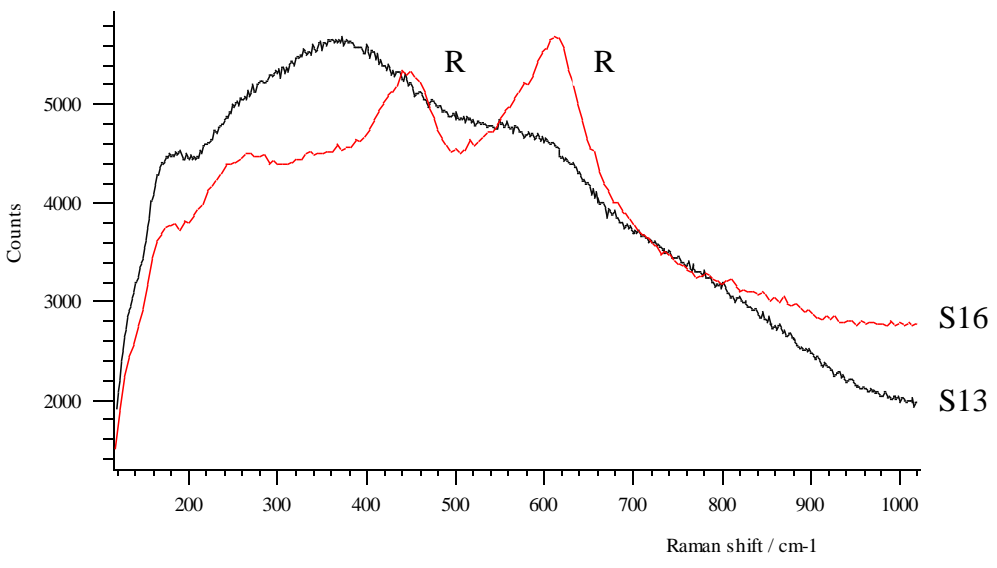

Figure 4. (a,b) Scanning electron microscopy (SEM) micrographs of as-deposited sample S13 produced at $350 \mathrm{kHz}$ onto glass substrates-FFE. Static-as-deposited; (c,d) SEM micrographs of as-deposited sample $\mathrm{S} 16$ produced at $350 \mathrm{kHz}$ onto glass substrates-FFE. $300 \mathrm{rpm}$ - as-deposited.

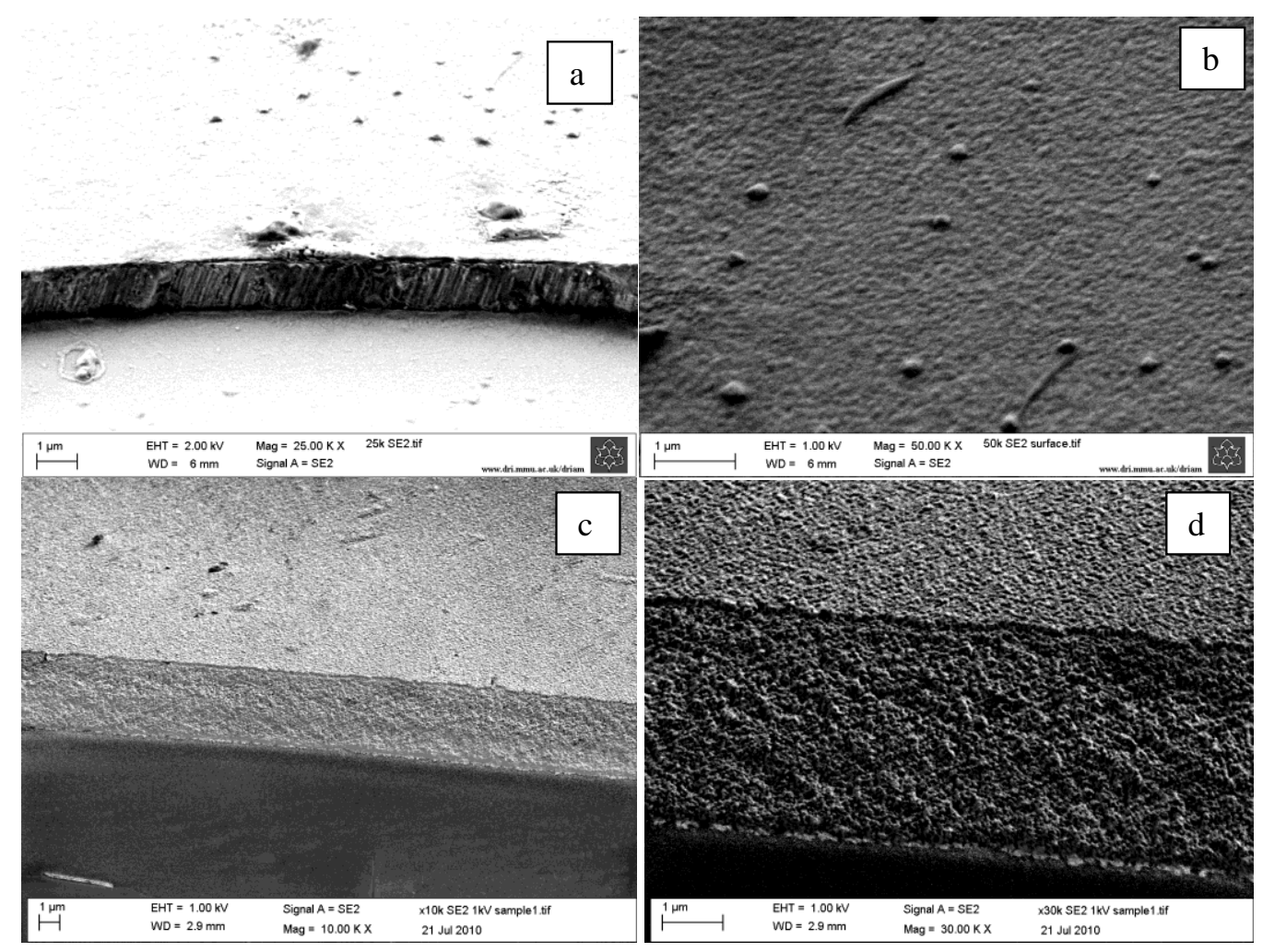




\subsubsection{Annealed Coatings}

The titania coatings were post-deposition annealed in air at temperatures in the range $400-700{ }^{\circ} \mathrm{C}$ and analysed by Raman spectroscopy and SEM. Table 1 describes the predominant crystal structure that formed after annealing for $10 \mathrm{~min}$ (as estimated from the relative intensities of the peaks in the spectra obtained from Raman spectroscopy) as a function of deposition conditions and annealing temperature.

From Table 1 it is clear that annealing temperature has a significant impact on the structure of the deposited films. The data imply that, significant structural transitions in these coatings generally occur between approximately $600{ }^{\circ} \mathrm{C}$ and $700{ }^{\circ} \mathrm{C}$. Crystallisation and grain growth are time and temperature dependent processes. The relatively short time of $10 \mathrm{~min}$ for annealing was, therefore, selected to allow structural evolution to be monitored as a function of temperature, since annealing for long periods of time would be likely to produce batches of coatings all with similar structures.

Figure 5 shows the Raman spectra for samples S5, S9 and S13 annealed at $600{ }^{\circ} \mathrm{C}$. S5 and S9 appear to be anatase and S13 shows evidence of a mixed rutile/anatase structure. However, further noticeable structural changes occurred when these samples were annealed at $700{ }^{\circ} \mathrm{C}$, as can be seen in Figure 6. While operating at $350 \mathrm{kHz}$ with the FFE central pole static (S13) formed a strongly rutile structure after annealing, varying the discharge frequency to either 100 or $225 \mathrm{kHz}$ (S5 and S9) resulted in the production of a mixed phase structure, which was predominantly anatase. The SEM micrographs of samples S5, S9 and S13 are shown in Figure 7a-f. Whilst S5 and S9 show smooth surfaces (except for a few defects) and almost featureless glassy fracture sections, S13 is somewhat rougher in appearance. S13 is also thinner, due to the lower deposition rate experienced at $350 \mathrm{kHz}$.

Figure 5. Raman spectra for samples S5, S9 and S13 produced at 100, 225 and $350 \mathrm{kHz}$ onto glass substrates-FFE. Static - Annealed at $600{ }^{\circ} \mathrm{C}$.

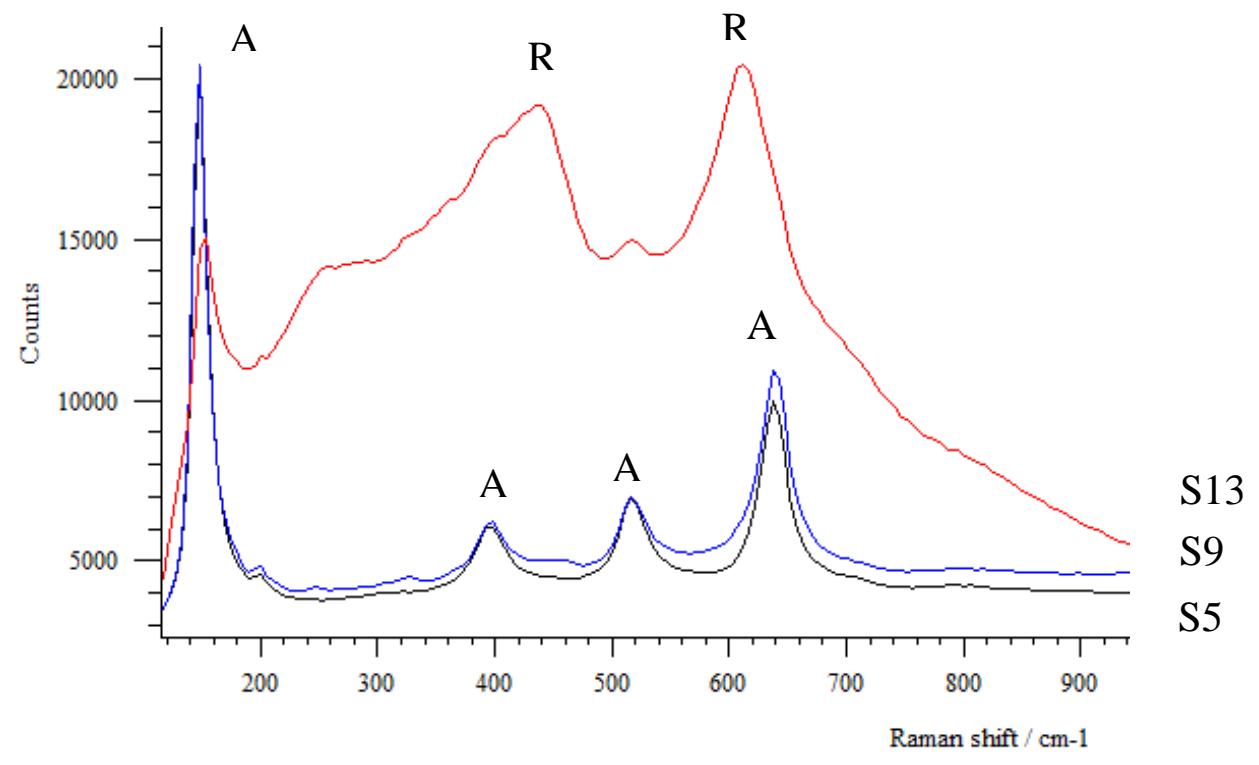


Figure 6. Raman spectra for samples S5, S9 and S13 produced at 100, 225 and $350 \mathrm{kHz}$ onto glass substrates-FFE. Static-Annealed at $700{ }^{\circ} \mathrm{C}$.

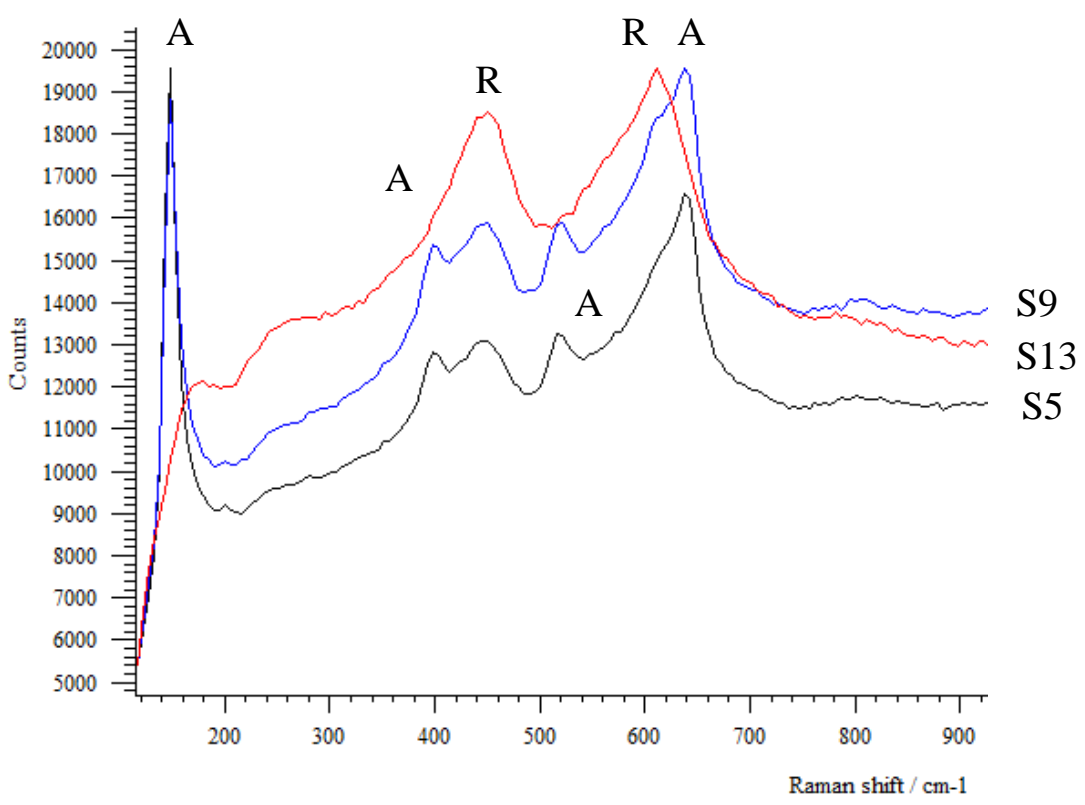

Figure 7. (a,b) SEM micrographs of sample S5 produced at $100 \mathrm{kHz}$ onto glass substrates - FFE. Static - annealed at $700{ }^{\circ} \mathrm{C}$ - structure: predominantly anatase with rutile structure. (c,d) SEM micrographs of sample S9 produced at $225 \mathrm{kHz}$ onto glass substrates - FFE. Static - annealed at $700{ }^{\circ} \mathrm{C}$ - structure: predominantly anatase with rutile structure. (e,f) SEM micrographs of sample S13 produced at $350 \mathrm{kHz}$ onto glass substrates-FFE. Static — annealed at $700{ }^{\circ} \mathrm{C}$ - structure: Rutile structure.

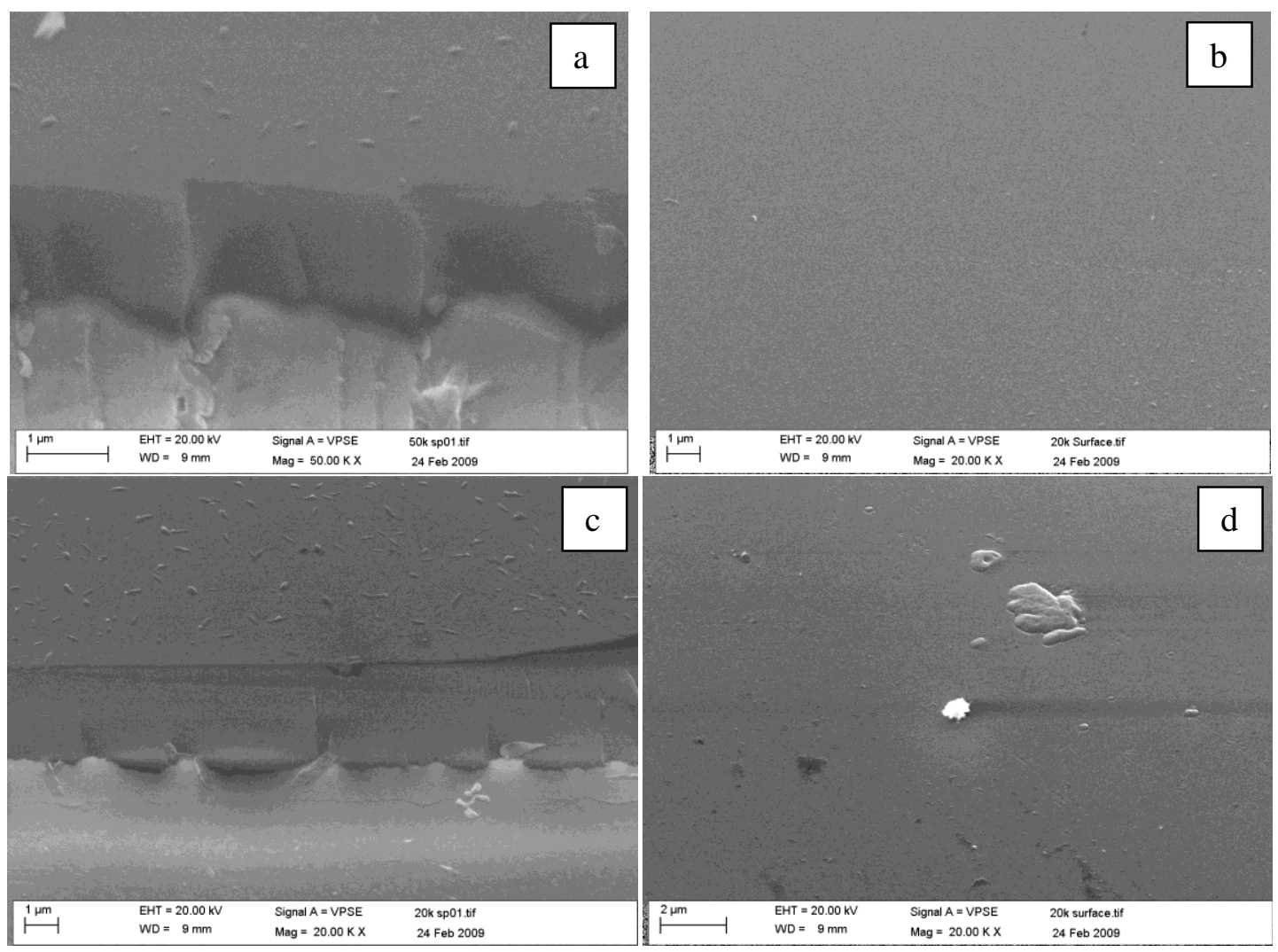


Figure 7. Cont.
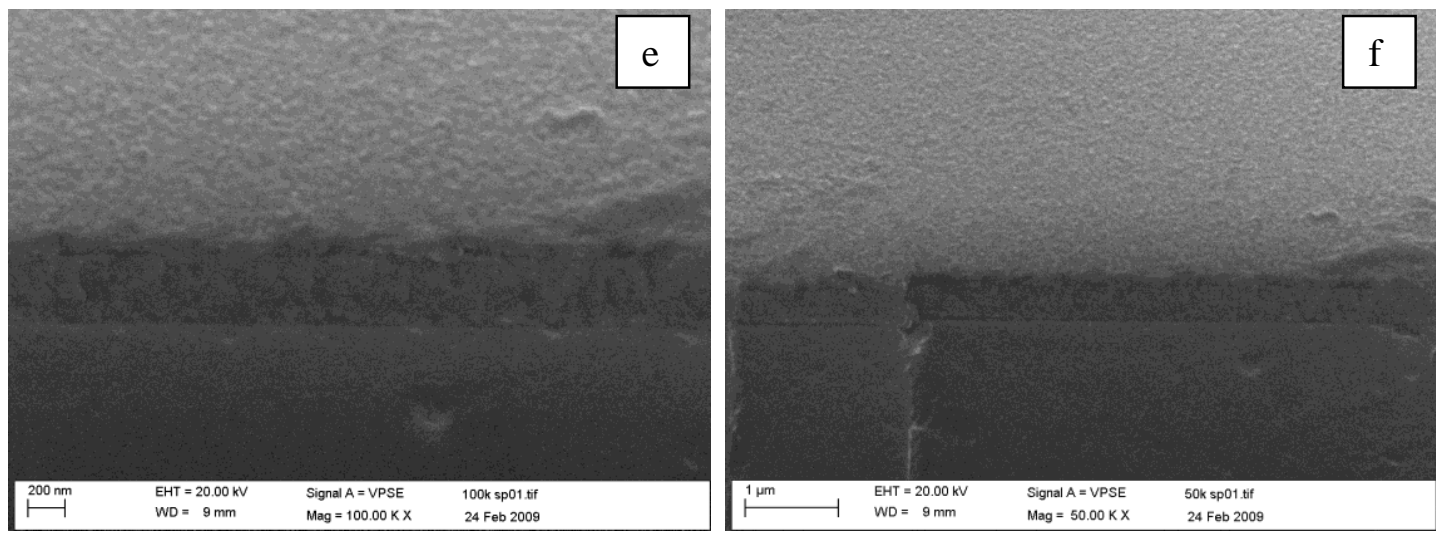

\subsection{Assessment of Photocatalytic Activity}

As mentioned above, in this study the photocatalytic activity was assessed in two ways. An initial scan of the samples was made using the photo-reduction reaction of resazurin dye. For the as-deposited coatings, the $\mathrm{Rz}$ showed no colour change after $40 \mathrm{~min}$ exposure to the UV lamps, indicating no discernible level of activity. In contrast, for the $\mathrm{TiO}_{2}$ coatings annealed at $600{ }^{\circ} \mathrm{C}$ and $700{ }^{\circ} \mathrm{C}$, there was a rapid blue to pink colour change within 2-3 min of exposure to the UV lamps indicating a high photocatalytic activity for the samples. However, it was not possible to differentiate between activity levels for different samples from the Rz tests. In order to do this, methyl orange tests were also carried out. Prior to testing the coatings, a sample of $\mathrm{MeO}$ was exposed to both light sources to measure the natural rate of degradation of the dye without contact with a photocatalyst. In addition, an as-deposited titania coating was also tested to give a baseline for the level of activity of an amorphous sample. This sample showed little activity, however, the $\mathrm{TiO}_{2}$ coatings annealed at 600 or $700{ }^{\circ} \mathrm{C}$ showed significant decreases in the magnitude of the $\mathrm{MeO} 464 \mathrm{~nm}$ absorption peak. An example of the effect is shown in Figure 8 for sample S5, which had a predominantly anatase structure after annealing at this temperature. These data and those from other tests were re-plotted to show the height of the peak as a function of exposure time to allow the relative degradation rates of the dye to be assessed. Figures 9 and 10, compare the results for coatings S5, S9 and S13 annealed at $600{ }^{\circ} \mathrm{C}$ and $700{ }^{\circ} \mathrm{C}$ with the amorphous titania sample and $\mathrm{MeO}$ without photocatalyst present (Figure 9 shows the results for exposure to UV lamps and Figure 10 shows the results for exposure to fluorescent lamps).

The data for the annealed coatings tested here show strong negative correlations of the form ' $y=-m x+c$ '; where the gradient, $-m$, gives the degradation rate of the methyl orange and $c$ is the initial concentration of the dye, which was kept constant for all tests. Linear regression analysis was, therefore, used to obtain values for $-m$ in each case, which can be used as a comparison of the photocatalytic activity of different coatings. These values are also included in Table 2. For convenience, modulus values of $m(|m|)$ are given in the table, and the degradation rates of the $464 \mathrm{~nm}$ methyl orange absorption peak following exposure to $365 \mathrm{~nm}$ UV lamps and fluorescent (Fl) lamps will be referred to as $|\mathrm{MeO}|_{\mathrm{UV}}$ and $|\mathrm{MeO}|_{\mathrm{Fl}}$, respectively. However, as the power flux to the samples varied for the different bulb types $\left(4 \mathrm{~mW} / \mathrm{cm}^{2}\right.$ for $\mathrm{UV}$ and $6.4 \mathrm{~mW} / \mathrm{cm}^{2}$ for the fluorescent tubes), these values have also been normalised to give the rate of decrease of peak height per milliwatt per $\mathrm{cm}^{2}$ of incident radiation. Normalised values of $|\mathrm{m}|$ are presented as a function of frequency, FFE oscillation 
speed and lamp type in Figure 11. This figure shows the results for the coatings annealed at $600{ }^{\circ} \mathrm{C}$, as these were marginally more active than those annealed at $700{ }^{\circ} \mathrm{C}$.

Figure 8. Photocatalytic degradation of $464 \mathrm{~nm}$ methyl orange absorption peak by titania sample S5 after annealing at $600{ }^{\circ} \mathrm{C}$ under exposure to $365 \mathrm{~nm} \mathrm{UV} \mathrm{lamps} \mathrm{at} 4 \mathrm{~mW} / \mathrm{cm}^{2}$.

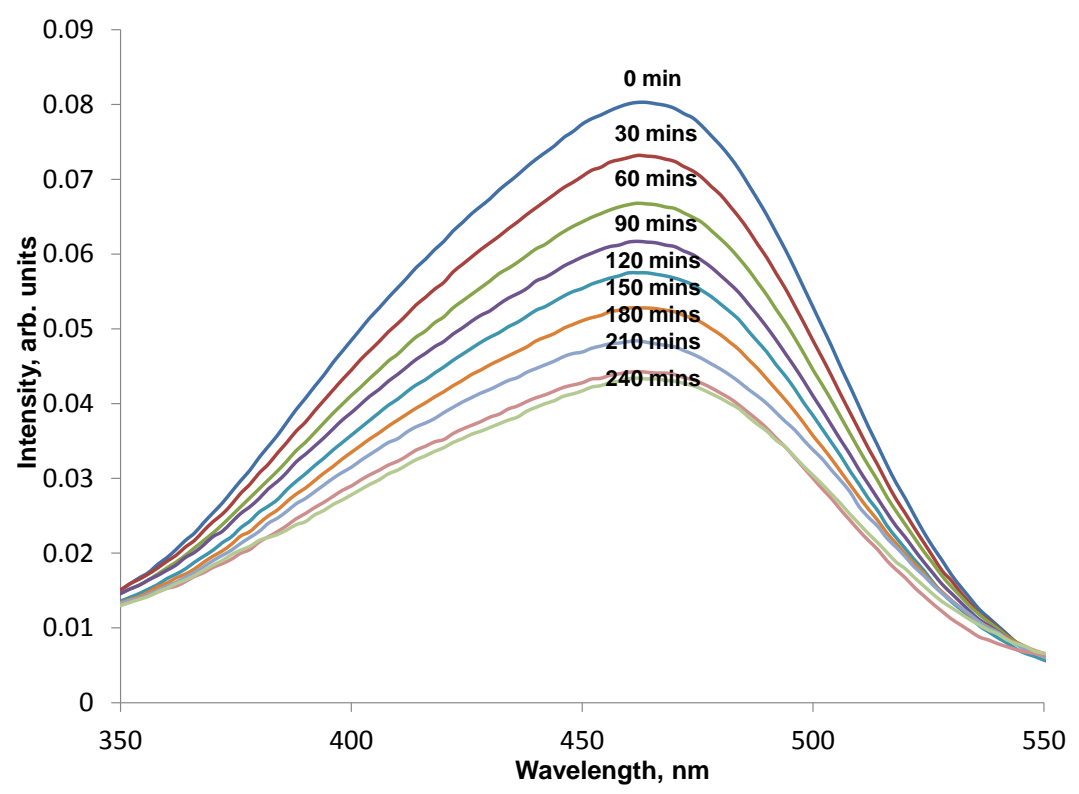

Figure 9. Degradation of $464 \mathrm{~nm}$ methyl orange $(\mathrm{MeO})$ absorption peak as a function of exposure time to UV lamps for titania samples S5, S9 and S13, annealed at $600-700{ }^{\circ} \mathrm{C}$, compared to an as-deposited coating and $\mathrm{MeO}$ without the presence of a photocatalyst. Linear regression analysis trendlines are also shown. Overall, the $\mathrm{TiO}_{2}$ coatings annealed at $600{ }^{\circ} \mathrm{C}$ showed the highest levels of activity in terms of the magnitude of the $\mathrm{MeO} 464 \mathrm{~nm}$ absorption peak as a function of exposure time to UV radiation. This may be related to the greater contribution of anatase phase in these samples.

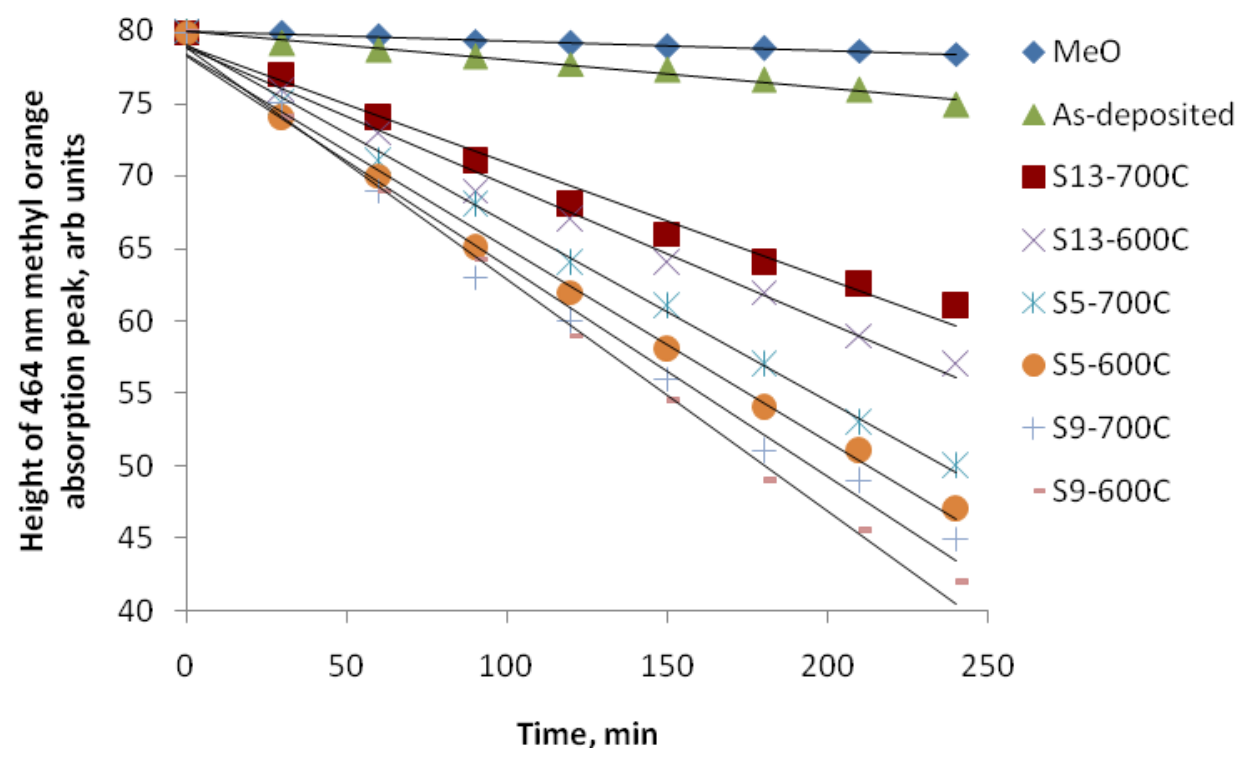


Figure 10. Degradation of $464 \mathrm{~nm}$ methyl orange absorption peak as a function of exposure time to fluorescent lamps for titania samples S5, S9 and S13, annealed at $600-700{ }^{\circ} \mathrm{C}$, compared to an as-deposited coating and $\mathrm{MeO}$ without the presence of a photocatalyst. Linear regression analysis trendlines are also shown. The $\mathrm{TiO}_{2}$ coatings annealed at $600{ }^{\circ} \mathrm{C}$ showed the highest levels of activity in terms of the magnitude of the MeO $464 \mathrm{~nm}$ absorption peak as a function of exposure time to fluorescent lamps.

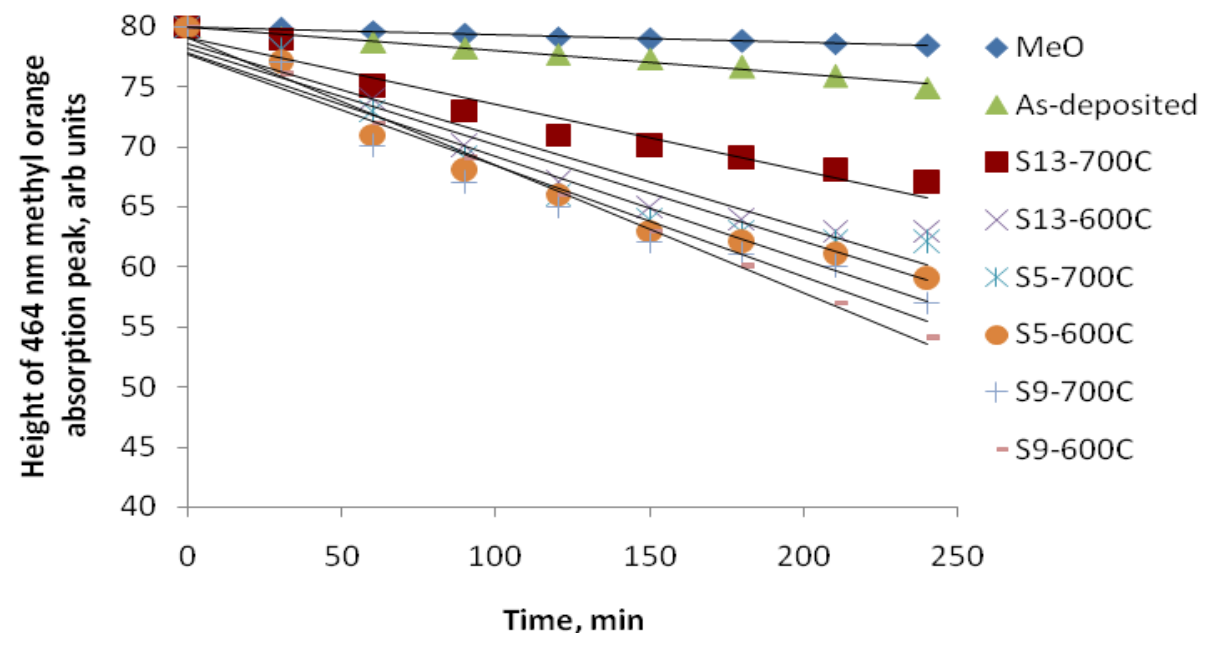

Table 2. Modulus values of degradation rates of $464 \mathrm{~nm}$ methyl orange $(\mathrm{MeO})$ absorption peak following exposure of annealed titania samples to $365 \mathrm{~nm}$ UV lamps and fluorescent (Fl) lamps solution.

\begin{tabular}{|c|c|c|c|c|c|}
\hline $\begin{array}{c}\text { Sample } \\
\text { No }\end{array}$ & $\begin{array}{c}\text { Predominant } \\
\text { Structure at } \\
600{ }^{\circ} \mathrm{C} \\
\end{array}$ & $\begin{array}{c}\text { MeO } \\
\text { gradient, } \\
\text { UV } \\
\end{array}$ & $\begin{array}{c}\text { Normalised MeO } \\
\text { UV rate, arbitrary } \\
\text { units }\left(\mathrm{min} / \mathrm{mW} \cdot \mathrm{cm}^{-2}\right)\end{array}$ & $\begin{array}{c}\text { MeO } \\
\text { gradient, } \\
\text { Fl } \\
\end{array}$ & $\begin{array}{l}\text { Normalised } \mathrm{MeO} \text { Fl } \\
\text { rate, } \text { arbitrary } \\
\text { units }\left(\mathrm{min} / \mathrm{mW} \cdot \mathrm{cm}^{-2}\right)\end{array}$ \\
\hline S1 & $\mathrm{RU}$ & 0.030 & 0.008 & 0.020 & 0.003 \\
\hline S2 & RU & 0.032 & 0.008 & 0.022 & 0.004 \\
\hline S3 & RU & 0.035 & 0.009 & 0.025 & 0.004 \\
\hline S4 & AN & 0.142 & 0.036 & 0.073 & 0.012 \\
\hline S5 & $\mathrm{AN}$ & 0.131 & 0.033 & 0.067 & 0.011 \\
\hline S6 & $\mathrm{AN}$ & 0.156 & 0.039 & 0.089 & 0.015 \\
\hline S7 & AN & 0.158 & 0.040 & 0.090 & 0.015 \\
\hline S8 & AN/RU & 0.121 & 0.030 & 0.058 & 0.010 \\
\hline S9 & AN & 0.158 & 0.040 & 0.096 & 0.016 \\
\hline S10 & AN/RU & 0.159 & 0.040 & 0.096 & 0.016 \\
\hline S11 & AN/RU & 0.160 & 0.040 & 0.096 & 0.016 \\
\hline S12 & AN/RU & 0.157 & 0.039 & 0.094 & 0.016 \\
\hline S13 & RU/AN & 0.110 & 0.028 & 0.075 & 0.013 \\
\hline S14 & RU & 0.099 & 0.025 & 0.049 & 0.008 \\
\hline S15 & RU & 0.097 & 0.024 & 0.051 & 0.009 \\
\hline S16 & RU & 0.095 & 0.024 & 0.051 & 0.009 \\
\hline
\end{tabular}


Figure 11. Comparison of methyl orange degradation rates by titania coatings annealed at $600{ }^{\circ} \mathrm{C}$ listed in Table 2 as a function of frequency, FFE oscillation speed and lamp type (*1000). The plot on the left represents the results for exposure to UV lamps and the plot on the right indicates the results for exposure to fluorescent lamps. Overall, the best activity levels under both UV and fluorescent light sources were obtained for the coatings deposited at pulse frequencies of $225 \mathrm{kHz}$ at an FFE speed of $300 \mathrm{rpm}$ and then annealed at $600{ }^{\circ} \mathrm{C}$. However, operating at frequencies of $100-225 \mathrm{kHz}$ at all given FFE oscillation speeds led to the production of layers which were similarly effective at degrading organic dyes, such as methyl orange, under the influence of UV and fluorescent light sources.

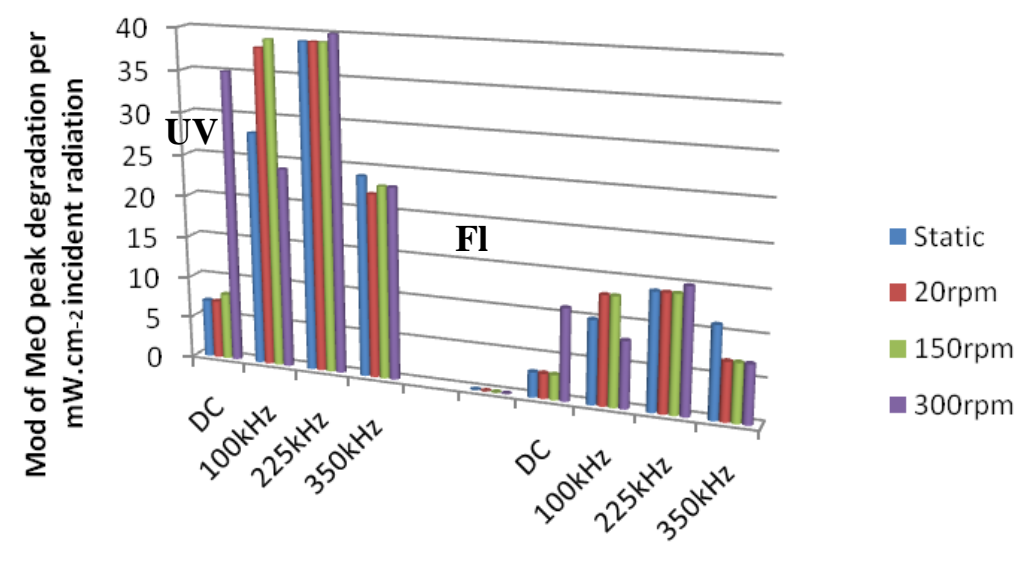

Frequency

\section{Discussion}

In the present work, titania films were deposited by DC and pulsed DC reactive magnetron sputtering using a full face erosion magnetron. This study indicated how the structures that form are dependent on both the deposition conditions (pulse frequency and FFE oscillation speed) and the post deposition annealing temperature. Deposited coatings that predominantly contained the anatase phase showed a dense structure and smooth surface with numerous random defects, whereas the surface features appeared somewhat rougher, but more regular in coatings that predominantly contained the rutile structure. It is interesting to note, however, that in this set of experiments, $\mathrm{R}_{\mathrm{a}}$ values for coatings which formed anatase structures were greater than those which formed the rutile phase. As an example, this effect can be seen in samples S4, S7 and S10 (all with anatase structures) produced at DC, 100 and $225 \mathrm{kHz}$ with $\mathrm{R}_{\mathrm{a}}$ values of 28,21 and $29 \mathrm{~nm}$, respectively. These results can be compared to those which formed rutile structures, such as $\mathrm{S} 1$ and $\mathrm{S} 14$ produced at $\mathrm{DC}$ and $350 \mathrm{kHz}$ with $\mathrm{R}_{\mathrm{a}}$ values of 9 nm each (See Table 1).

Regarding the photocatalytic activity of the annealed samples, the resazurin test initially provided a quick indication of whether the surfaces were active or not, but was not capable in these tests of differentiating between different levels of activity. Photocatalytic activity of the coatings annealed at 400 to $700{ }^{\circ} \mathrm{C}$ was, therefore, quantified by the methyl orange test. The $\mathrm{TiO}_{2}$ coatings annealed at $600{ }^{\circ} \mathrm{C}$ showed the highest levels of activity in terms of the degradation of the $\mathrm{MeO} 464 \mathrm{~nm}$ absorption peak as a function of exposure time to UV radiation. This may be related to the greater contribution of anatase in these samples. It is interesting to note that reasonable levels of activity were also observed for the coatings exposed to the fluorescent tubes. The normalised level of activity for these coatings 
were around $35 \%-45 \%$, in some cases, of those recorded for the samples exposed to the $365 \mathrm{~nm} \mathrm{UV}$ tubes. However, only $8 \%$ of the power flux from the fluorescent tubes is in the range $300-400 \mathrm{~nm}$, which implies that the coatings may display some level of activity in the visible range (although a UV filter would be needed to confirm this). This may be a result of the mixed anatase/rutile structures, but it has important implications for possible applications in situations where surfaces are illuminated by artificial lighting.

It is also apparent from the results presented here that photocatalytic activity is also dependent on surface roughness [45]. Indeed, there is a clear correlation between $R_{a}$ value and photocatalytic activity, as can be seen in Figure 12. This might be expected, as an increase in $R_{a}$ value implies an increase in the surface area of the coating in contact with the $\mathrm{MeO}$ solution. From Table 1 it can also be noted that the $\mathrm{R}_{\mathrm{a}}$ value, in turn, is weakly dependant on the thickness of the films (i.e., deposition rate).

Figure 12. Comparison of methyl orange degradation rates as a function of $R_{\mathrm{a}}$ values (nm) and exposure time to UV and fluorescent lamps $(* 1000)$ for coatings annealed at $600{ }^{\circ} \mathrm{C}$ listed in Table 1 . It can be seen that there is a clear correlation between $R_{\mathrm{a}}$ value and photocatalytic activity.

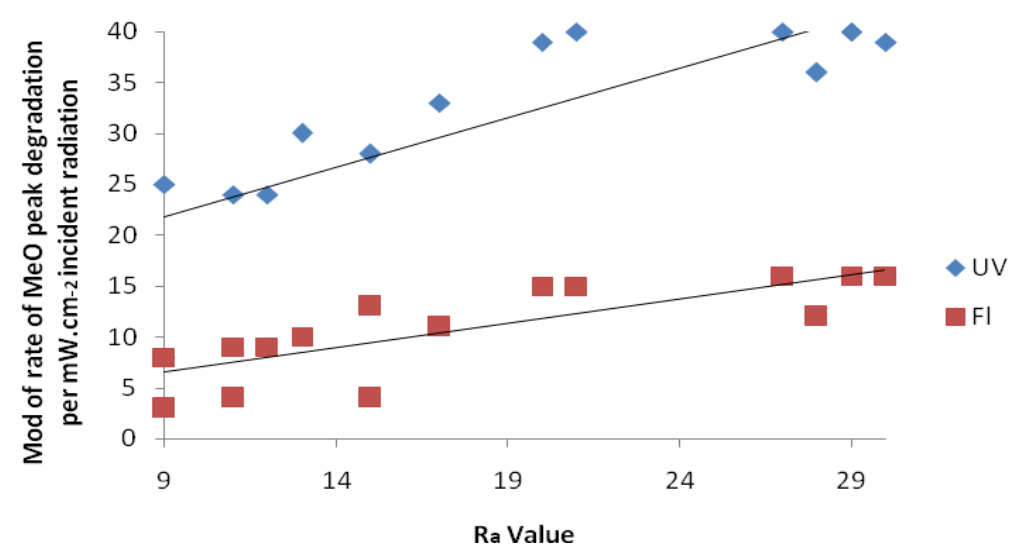

Considering Figure 11, it appears that pulse frequency is the most significant factor in determining crystalline structure and, therefore, photocatalytic activity level after these coatings had been annealed. FFE oscillation speed had a marginal, secondary effect, on activity levels. Overall, the best activity levels under both UV and fluorescent light sources were obtained for the coatings deposited at pulse frequencies of $225 \mathrm{kHz}$ at an FFE speed of $300 \mathrm{rpm}$ and then annealed at $600{ }^{\circ} \mathrm{C}$. However, operating at frequencies of $100-225 \mathrm{kHz}$ at all given FFE oscillation speeds led to the production of layers which were similarly effective at degrading methyl orange, under the influence of UV and fluorescent light sources.

Considering the various structures that formed after the annealing of these films, it is then possible to distinguish an optimum area for the formation of anatase coatings with highest level of activity, which is shown in Figure 13. This clarifies, in the form of a zone diagram, the relationship between pulse frequency, FFE oscillation speed and the resultant titania structures that formed after being annealed at $600{ }^{\circ} \mathrm{C}$. It can be seen that by manipulating pulse frequency and FFE oscillation speed, titania coatings of all structures (amorphous, anatase, rutile and mixed phase) can be achieved.

The well-known Löbl model [46] showed the relationship between the energy of particles impinging on the substrate, substrate temperature and the phases of PVD titania coatings. Figure 13 can 
be described as an alternative model that complies with that of Löbl, in which new influential factors in pulse magnetron sputtering have been considered. Figure 13 shows that in the range of $100-225 \mathrm{kHz}$ (50\% duty) with FFE oscillation speed of $0-150 \mathrm{rpm}$ the formation of anatase is preferred. In contrast; operating at higher FFE oscillation speed led to an apparent increase in the contribution of rutile phase in the deposited films and this contribution was even higher for coatings produced at $350 \mathrm{kHz}$. The underlying mechanisms behind the observed structural changes will be the subject of future papers.

Figure 13. Zone diagram showing relationship between coating structure, frequency, and the FFE oscillation speed of titania coatings at annealing temperature of $600{ }^{\circ} \mathrm{C}$. An optimum area for the formation of anatase coatings with high, mid and low level of activity has been highlighted in red, green and yellow colours, respectively. Considering the various structures that formed after the annealing of these coatings, it is then possible to distinguish an optimum area for the formation of anatase coatings with highest level of activity, which is shown in this figure.

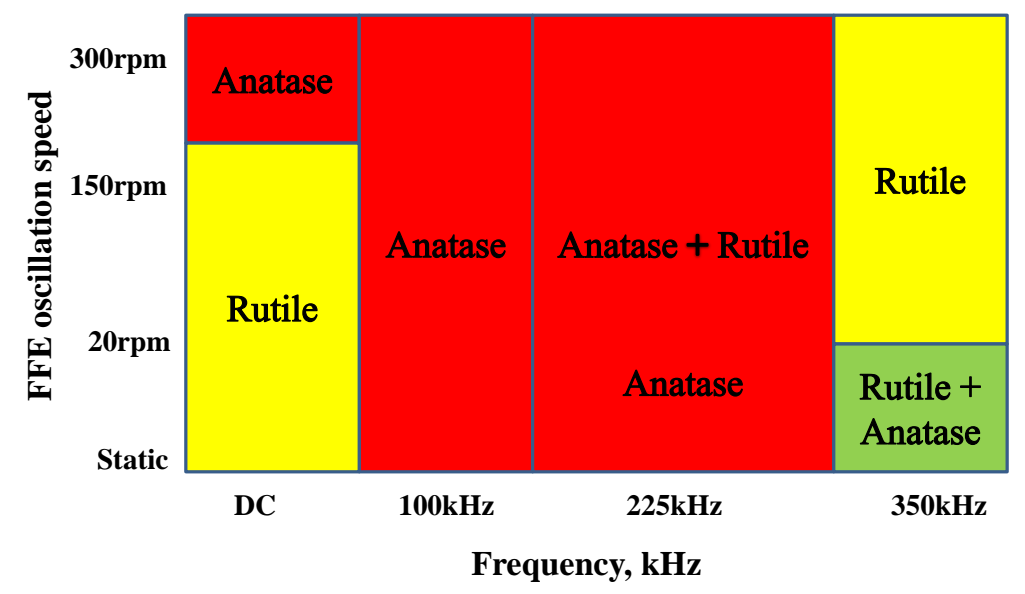

\section{Conclusions}

The present study demonstrated that the pulsed magnetron sputtering technique using a Full Face Erosion (FFE) magnetron produces coatings of uniform thickness at reasonable deposition rates. It was also found that the structures of the coatings are strongly dependent on both the deposition conditions (pulse frequency and FFE oscillation speed) and the post deposition annealing temperature. In the latter case, for many samples significant structural transitions occurred over the range of approximately $600-700{ }^{\circ} \mathrm{C}$. After annealing at $600{ }^{\circ} \mathrm{C}$ samples with predominantly anatase structures were produced in which the contribution of the rutile phase can become more dominant by further increasing the annealing temperature. Furthermore, it was found that for the $\mathrm{TiO}_{2}$ coatings annealed at $600{ }^{\circ} \mathrm{C}$ or $700{ }^{\circ} \mathrm{C}$, significant levels of photo-activity were observed under exposure to UV light. Also, the normalised level of activity for the coatings exposed to the fluorescent light source was around $35 \%-45 \%$, of those samples exposed to the $365 \mathrm{~nm}$ UV tubes. Finally, it was demonstrated that the optimum frequency and duty to produce layers with high crystallinity in the anatase phase was in the range of $100-225 \mathrm{kHz}$ (50\% duty) at all given FFE oscillation speeds. 


\section{Conflicts of Interest}

The authors declare no conflict of interest.

\section{References}

1. Gloss, D.; Frach, P.; Zywitzki, O.; Klinkenberg, S.; Gottfried, C. Photocatalytic titanium dioxide thin films prepared by reactive pulse magnetron sputtering at low temperature. Surf. Coat. Technol. 2005, 200, 967-971.

2. Minemoto, T.; Negami, T.; Nishiwaki, S.; Takakuraa, H.; Hamakawa, Y. Preparation of $\mathrm{Zn}_{1-\mathrm{x}} \mathrm{Mg}_{\mathrm{x}} \mathrm{O}$ films by radio frequency magnetron sputtering. Thin Solid Films 2000, 372, 173-176.

3. Fujishima, A.; Rao, T.N.; Tryk, D.A. Titanium dioxide photocatalysis. J. Photochem. Photobiol. 2000, 1, 1-21.

4. Kluth, O.; Rech, B.; Houben, L.; Wieder, S.; Schöpe, G.; Beneking, C.; Wagner, H.; Löffl, A.; Schock, H.W. Texture etched $\mathrm{ZnO}$ :Al coated glass substrates for silicon based thin film solar cells. Thin Solid Films 1999, 351, 247-253.

5. Fortunato, E.; Nunes, P.; Costa, D.; Brida, D.; Ferreira, I.; Martins, R. Characterisation of aluminium doped zinc oxide thin films deposited on polymeric substrates. Vacuит 2002, 64, 233-236.

6. Szyszka, B. Transparent and conductive aluminum doped zinc oxide films prepared by mid-frequency reactive magnetron sputtering. Thin Solid Films 1999, 251, 164-169.

7. Ding, X.Z.; Liu, X.H. Correlation between anatase-to-rutile transformation and grain growth in nanocrystalline titania powders. J. Mat. Res. 1998, 13, 2556-2559.

8. Sicha, J.; Musil, J.; Meissner, M.; Cerstvy, R. Nanostructure of photocatalytic $\mathrm{TiO}_{2}$ films sputtered at temperatures below $200{ }^{\circ}$ C. Appl. Surf. Sci. 2008, 254, 3793-3800.

9. Rawat, R.S.; Aggarwal, V.; Hassan, M.; Lee, P.; Springham, S.V.; Tan, T.L.; Lee, S. Nano-phase titanium dioxide thin film deposited by repetitive plasma focus: Ion irradiation and annealing based phase transformation and agglomeration. Appl. Surf. Sci. 2008, 255, 2932-2941.

10. Bendavid, A.; Martin, P.J.; Preston, E.W. The effect of pulsed direct current substrate bias on the properties of titanium dioxide thin films deposited by filtered cathodic vacuum arc deposition. Thin Solid Films 2008, 517, 494-499.

11. Long, H.; Yang, G.; Chen, A.; Li, Y.; Lu, P. Growth and characteristics of laser deposited anatase and rutile $\mathrm{TiO}_{2}$ films on Si substrates. Thin Solid Films 2008, 517, 745-749.

12. Srivatsa, K.M.K.; Bera, M.; Basu, A. Pure brookite titania crystals with large surface area deposited by plasma enhanced chemical vapour deposition technique. Thin Solid Films 2008, 516, 7443-7446.

13. Fusi, M.; Russo, V.; Casari, C.S.; Bassi, A.L.; Bottani, C.E. Titanium oxide nanostructured films by reactive pulsed laser deposition. Appl. Surf. Sci. 2009, 255, 5334-5337.

14. Ribarsky, M.W. Titaniumm dioxide $\left(\mathrm{TiO}_{2}\right)$ (Rutile). Handb. Opt. Constants Solids 1997, 1, 795-804.

15. Henderson, P.S.; Kelly, P.J.; Arnell, R.D.; Bäcker, H.; Bradley, J.W. Investigation into the properties of titanium based films deposited using pulsed magnetron sputtering. Surf. Coat. Technol. 2003, 174, 779-783. 
16. Kelly, P.J.; Arnell, R.D. The influence of deposition parameters on the structure of Al, $\mathrm{Zr}$ and W coatings deposited by closed-field unbalanced magnetron sputtering. Surf. Coat. Technol. 1996, 86-87, 425-431.

17. Kelly, P.J.; Bradley, J.W. Pulsed magnetron sputtering-Process overview and applications. J. Opto. Adv. Mat. 2009, 11, 1101-1107.

18. Yates, H.M.; Brook, L.A.; Ditta, I.B.; Evans, P.; Foster, H.A.; Sheel, D.W.; Steele, A. Photo-induced self-cleaning and biocidal behaviour of titania and copper oxide multilayers. J. Photochem. Photobiol. A Chem. 2008, 197, 197-205.

19. Zhang, W.; Li, Y.; Zhu, S.; Wang, F. Fe-doped photocatalytic $\mathrm{TiO}_{2}$ film prepared by pulsed DC reactive magnetron sputtering. J. Vac. Sci. Technol. 2003, A21, 1877-1882.

20. Kok, Y.N.; Kelly, P.J. Properties of pulsed magnetron sputtered $\mathrm{TiO}_{2}$ coatings grown under different magnetron configurations and power deliver modes. Plasma Proc. Polym. 2007, 4, 299-304.

21. Zhao, L.; Jiang, Q.; Lian, J. Visible-light photocatalytic activity of nitrogen-doped $\mathrm{TiO}_{2}$ thin film prepared by pulsed laser deposition. Appl. Surf. Sci. 2008, 254, 4620-4625.

22. Rampaul, A.; Parkin, I.P.; O’Neill, S.A.; de Souza, J.; Mills, A.; Elliot, N. Titania and tungsten doped titania thin films on glass; active photocatalysts. Polyhedron 2003, 22, 35-44.

23. Park, S.E.; Joo, H.; Kang, J.W. Effect of impurities in $\mathrm{TiO}_{2}$ thin films on trichloroethylene conversion. Sol. Energy Mater. Sol. Cells 2004, 83, 39-53.

24. Ratova, M.; Kelly, P.J.; West, G.; Lordanova, I. Enhanced properties magnetron sputtered photocatalytic coatings via transition metal doping. Surf. Coat. Technol. 2013, 228, 544-549.

25. Kelly, P.J.; West, G.; Kok, Y.N.; Bradley, J.W.; Swindells, I.; Clarke, G.C.B. A comparison of the characteristics of planar and cylindrical magnetrons operating in pulsed DC and AC modes. Surf. Coat. Technol. 2007, 202, 952-956.

26. Fernández, A.; Lassaletta, G.; Jiménez, V.M.; Justo, A.; González-Elipe, A.R.; Herrmann, J.M.; Tahiri, H.; Ait-Ichou, Y. Preparation and characterization of $\mathrm{TiO}_{2}$ photocatalysts supported on various rigid supports (glass, quartz and stainless steel). Comparative studies of photocatalytic activity in water purification. Appl. Catal. B Env. 1995, 7, 49-63.

27. Zhu, J.; Deng, Z.; Chen, F.; Zhang, J.; Chen, H.; Anpo, M.; Huang, J.; Zhang, L. Hydrothermal doping method for preparation of $\mathrm{Cr}^{3+}-\mathrm{TiO}_{2}$ photocatalysts with concentration gradient distribution of $\mathrm{Cr}^{3+}$. Appl. Catal. B Env. 2006, 62, 329-325.

28. Kim, J.Y.; Park, C.; Yoon, J. Developing a testing method for antimicrobial efficacy on $\mathrm{TiO}_{2}$ photocatalytic products. Environ. Eng. Res. 2008, 13, 136-140.

29. Evans, P.; Pemble, M.E.; Sheel, D.W.; Yates, H.M. Multifunctional self-cleaning thermochromic films by atmospheric pressure chemical vapour deposition. J. Photochem. Photobiol. A Chem. 2007, 189, 387-397.

30. Evans, P.; English, T.; Hammond, D.; Pemble, M.E.; Sheel, D.W. The role of $\mathrm{SiO}_{2}$ barrier layers in determining the structure and photocatalytic activity of $\mathrm{TiO}_{2}$ films deposited on stainless steel. Appl. Catal. A Gen. 2007, 321, 140-146.

31. Kenanakis, G.; Giannakoudakis, Z.; Vernardou, D.; Savvakis, C.; Katsarakis, N. Photocatalytic degradation of stearic acid by $\mathrm{ZnO}$ thin films and nanostructures deposited by different chemical routes. J. Catal. Today 2010, 151, 34-38. 
32. Brook, L.A.; Evans, P.; Foster, H.A.; Pembleb, M.E.; Steele, A.; Sheel, D.W.; Yates, H.M. Highly bioactive silver and silver/titania composite films grown by chemical vapour deposition. J. Photochem. Photobiol. A Chem. 2007, 187, 53-63.

33. Evans, P.; Pemble, M.E.; Sheel, D.W. Precursor-directed control of crystalline type in atmospheric pressure CVD growth of $\mathrm{TiO}_{2}$ on stainless steel. J. Chem. Mat. 2006, 18, 5750-5755.

34. Guettai, N.; Amar, H.A. Photocatalytic oxidation of methyl orange in presence of titanium dioxide in aqueous suspension, Part I, Parametric Study. Desalination 2005, 185, 427-437.

35. Hazan, R.; Sreekantan, S.; Lockman, Z.; Mat, I. A study on photocatalytic degradation of methyl orange using carbon doped $\mathrm{TiO}_{2}$ nanotubes. J. Fund. Sci. 2010, 96, 355-365.

36. Carcel, R.A.; Andronic, L.; Duta, A. $\mathrm{Cd}^{2+}$ modified $\mathrm{TiO}_{2}$ for methyl orange photodegradation. Rev. Roum. Chim. 2009, 54, 309-312.

37. Kim, S.; Ehrman, S.H. Photocatalytic activity of a surface-modified anatase and rutile titania nanoparticle mixture. J. Col. Interf. Sci. 2009, 338, 304-307.

38. Onifade, A.A.; Kelly, P.J. The influence of deposition parameters on the structure and properties of magnetron-sputtered titania coatings. Thin Solid Films 2006, 494, 8-12.

39. Ohno, S.; Takasawa, N.; Sato, Y.; Yoshikawa, M.; Suzuki, K.; Frach, P.; Shugesato, Y. Photocatalytic $\mathrm{TiO}_{2}$ films deposited by reactive magnetron sputtering with unipolar pulsing and plasma emission control systems. Thin Solid Films 2006, 496, 126-130.

40. Evans, P.; Mantke, S.; Mills, A.; Robinson, A.; Sheel, D.W. A comparative study of three techniques for determining photocatalytic activity. J. Photochem. Photobiol. A Chem. 2007, 188, 387-391.

41. Mills, A.; McGrady, M. A study of new photocatalyst indicator inks. J. Photochem. Photobiol. A Chem. 2008, 193, 228-236.

42. Mills, A.; Hepburn, J.; McFarlane, M. A novel, fast-responding, indicator ink for thin film photocatalytic surfaces. ACS Appl. Mat. Interf. 2009, 1, 1163-1165.

43. Coutinho, C.A.; Gupta, V.K. Photocatalytic degradation of methyl orange using polymer-titania microcomposites. J. Col. Interf. Sci. 2009, 333, 64.

44. Bates, R.I.; Arnell, R.D. Alloy coatings by dual magnetron sputter barrel plating. Surf. Coat. Technol. 1994, 68-69, 686-690.

45. Zywitzki, O.; Modes, T.; Frach, P.; Gloss, D. Effect of Structure and Roughness on Photocatalytic Properties of $\mathrm{TiO}_{2}$. In Proceedings of European Materials Research Society (EMRS): European Materials Research Society (E-MRS) Spring Meeting, Strasbourg, France, 28 May-1 June 2007.

46. Löbl, P.; Huppertz, M.; Mergel, D. Nucleation and growth in $\mathrm{TiO}_{2}$ films prepared by sputtering and evaporation. Thin Solid Films 1994, 251, 72-79.

(C) 2013 by the authors; licensee MDPI, Basel, Switzerland. This article is an open access article distributed under the terms and conditions of the Creative Commons Attribution license (http://creativecommons.org/licenses/by/3.0/). 